an inversion to determine the variation of rotation in the core. However, the authors have carried out a least-squares fit to the data of various simple parametrizations of rotation, in most cases representing angular velocity as being constant over a few discrete shells and constraining rotation in the outer parts of the Sun to fit the results such as those shown in the figure. The values for the angular velocity depend on the assumed extent of the shells; but in all cases the results show regions rotating at well below the surface rate, confirming the initial impression (the results in the figure show a similar tendency, albeit with considerable uncertainty).

The physical origin of this behaviour is unclear. Elsworth et al. point out that because the minimum energy state is one of uniform rotation, the slowly rotating interior might be a transient state, possibly changing with solar cycle, or it might be caused by stresses resulting from material motion in the core or from magnetic fields. These possibilities will undoubtedly lead to extensive theoretical investigations.

Observations of solar internal rotation will soon be extended by the results from the Global Oscillation Network Group (GONG) project and the helioseismic instruments on the Solar and Heliospheric Observatory (SOHO) satellite to be launched late this year. Furthermore, continuation of the BiSON observations through at least one solar cycle, to test for the possible time-dependence of rotation, would be extremely valuable. The overall outcome may well be a significant change in our understanding of moderate-mass stars.

Jørgen Christensen-Dalsgaard is at the Theoretical Astrophysics Center, Danish National Research Foundation, and Institute of Physics and Astronomy, University of Aarhus, DK-8000 Aarhus C, Denmark.

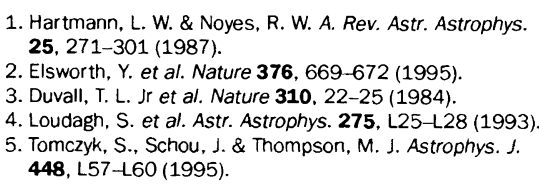

\title{
Female anti-male attack
}

\section{Harald von Boehmer}

THE immune system of females has been known to respond to male-specific transplantation (H-Y) antigens for some forty years, but the gene that encodes them has proved elusive. Now, on page 695 of this issue, Scott et al. ${ }^{1}$ report that the $S m c y$ (for selected mouse cDNA on Y chromosome $)^{2}$ gene is the origin of $\mathrm{H}-\mathrm{Y}$ antigen, a result that was achieved through cosmid transfection and sequence analysis. Their conclusions are verified in an independent study by Wang et al. ${ }^{3}$, whose sequence of peptides isolated from class I molecules of the major histocompatibility complex (MHC) on the surface of cells from human males shows that they were derived from the human homologue of Smcy.

$\mathrm{H}-\mathrm{Y}$ antigens were identified as a result of the rejection of male skin grafts by female mice from the same inbred mouse strain $^{4}$. It was argued that genes on the $Y$ chromosome control expression of $\mathrm{H}-\mathrm{Y}$ antigens ${ }^{5}$ and that male-specific surface antigens could have a role in formation of the testes ${ }^{6}$, an intriguing idea that fell down when it was found that mice lacking $\mathrm{H}-\mathrm{Y}$ antigens still developed testes ${ }^{7}$.

Of course in the early days of H-Yspecific immunity, the transport of intracellular peptides by MHC molecules to the cell surface was unheard of. The fact established later that cytolytic $T$ cells recognize $\mathrm{H}-\mathrm{Y}$ antigens in the context of MHC molecules ${ }^{8}$ was then consistent with the suggestion that male-specific peptides could be degradation products of intracellular proteins that do not reach the cell surface in their entirety. It also became apparent that $\mathrm{H}$-Y-specific immune responses could be generated in some mouse strains but not others, depending on whether or not these expressed 'permissive' MHC molecules 9,10 that could present $\mathrm{H}-\mathrm{Y}$ peptides. This fact, together with the notion that $\mathrm{H}-\mathrm{Y}$ antigens are expressed on many different target cells, suggested that there could only be a limited variety of ubiquitously expressed, male-specific peptides.

Interestingly, the cytolytic response was not only controlled by permissive class I but also by permissive class II MHC genes, and it was found that $\mathrm{H}$-Y-specific class-II-MHC-restricted T-helper cells and $\mathrm{H}$-Y-specific class-I-restricted cytolytic T cells cooperated in vivo to bring about an effective immune response ${ }^{11}$. In fact, $\mathrm{H}$-Y-specific helper and cytolytic T-cell clones were isolated and used as tools to detect the surface expression of H-Y peptides. It is curious that the origin of malespecific peptides should have remained so

1. Scott, D. M. et al. Nature 376, 695-698 (1995).

2. Agulnik, A. I., Mitchell, M. J., Lerner, J. L., Woods,

D. R. \& Bishop, C. E. Hum. molec. Genet. 3, 873-878 (1994)

3. Wang, W. et al. Science (in the press)

4. Eichwald, E. J. \& Silsmer, C. R. Transplant. Bull. 2. 154-155 (1955).

5. Gasser, D. L. \& Silvers, W. K. Adv. Immun. 15, 215-247 (1972).

6. Wachtel, S., Onno, S., Koo, G. C. \& Boyse, E. A. Nature 257, 235-236 (1975). elusive, for three reasons - the $\mathrm{H}-\mathrm{Y}$ response provided a neat illustration of MHC-restricted antigen recognition and thymic selection; the first MHCrestricted $\mathrm{T}$-cell clone to be isolated was $\mathrm{H}-\mathrm{Y}$-specific (and specific for MHC alloantigens); and, finally, the first mice reported to be transgenic for the T-cell receptor expressed $\mathrm{H}$-Y-specific receptors.

The identification by Scott et al. ${ }^{1}$ and Wang et $a l^{3}$ of the Smcy gene as the originator of $\mathrm{H}-\mathrm{Y}$ peptides meets all expectations that could be derived from earlier studies of $\mathrm{H}$-Y-specific immune responses: the $S m c y$ gene is ubiquitously expressed in males only ${ }^{2}$ and the malespecific peptides are encoded in regions of the Smcy genes that differ in their sequence from the $S m c x$ gene $^{12}$, which is homologous to Smcy but located on the $\mathrm{X}$ chromosome and ubiquitously expressed in both females and males. This explains why the $X X$ female can strike against an $\mathrm{XY}$ male, but the male cannot reciprocate.

It is probably not a mere coincidence that both the suspected murine H-Y peptide and the human peptide are encoded by $S m c y$, because so far this is the only ubiquitously expressed gene to have been identified on the segment of the $\mathrm{Y}$ chromosome that controls immunity to $\mathrm{H}-\mathrm{Y}$. Other genes identified in that region are the zinc-finger genes $Z f y-1$ and $Z f y-2$, as well as the Ubely-1 gene (for a review, see ref. 2), which are exclusively expressed in the testes.

The tracing of $\mathrm{H}-\mathrm{Y}$ peptides back to the Smcy gene at last satisfactorily demystifies the $\mathrm{H}-\mathrm{Y}$-specific transplantation reaction which, in spite of its clinical relevance, represents a biologically irrelevant consequence of the ubiquitous expression of a gene whose location on the Y chromosome has been conserved over a hundred million years ${ }^{2}$. What does remain a mystery, however, is the function of the Smcy gene during very early expression in embryogenesis and later on in a variety of tissues including the testes. Given the efficiency of transgenesis and gene targeting in the mouse, this should not remain a mystery for long.

Harald von Boehmer is at the Basel Institute for Immunology, Grenzacherstrasse 487, CH-4005 Basel, Switzerland, and at Institut Necker, INSERM Unité 373, rue de Vaugirard 156, F-75730 Paris Cedex 15, France.

\footnotetext{
7. Burgoyne, P. S., Levy, E. R. \& McLaren, A. Nature 320 170-172 (1986)

8. Gordon, R. D. Simpson, E. \& Samelson, L. J. exp. Med. 142, 1108-1120 (1975).

9. Simpson, E. \& Gordon, R. Immun. Rev. 35. 59-75 (1977),

10. von Boehmer, H., Fathman, C. G. \& Haas, W. Eur. J. Immun. 7, 443-447 (1977).

11. von Boehmer, H. \& Haas, W. J. exp. Med. 150 1134-1142 (1979).

12. Agulnik, A. I. et al. Hum. molec. Genet. 3, 879-884 (1994).
} 